\title{
LEIBNIZ E HUME SOBRE A INDIFERENCA
}

Déborah Danowski ${ }^{1}$

\begin{abstract}
RESUMO $O$ artigo busca comparar algumas das razões diversas subjacentes à crítica comum de Leibniz e de Hume à idéia de uma liberdade de indiferença. Em Leibniz, como a ligação harmônica entre as substâncias individuais concretas se dá exclusivamente por meio de relações intrínsecas a seus conceitos completos, só é possível haver indiferença no domínio das noções incompletas ou de razão, o único em que podemos privilegiar e isolar termos e relações uns dos outros. Em Hume, a impossibilidade de fato de escaparmos da regularidade das relações extrínsecas, que, pela aplicação das regras gerais, acabam por se estender a toda a experiência, ainda que sem garantias racionais, relega a indiferença à situação quase fictícia de um estado original da mente, anterior à experiência, ou então ao domínio restrito de situações que provocam o afloramento desse estado no interior da experiência.
\end{abstract}

Palavras-chave: Leibniz, Hume, indiferença

ABSTRACT In this paper I briefly compare some of the divergent reasons given by Leibniz and Hume for their common criticism against the idea of liberty of indifference. For Leibniz, the harmonic connection among concrete individual substances is expressed exclusively by means of relations that are intrinsic to their complete concepts, so that indifference can only exist within the sphere of incomplete notions or concepts of reason, the only one where it is possible to isolate a few terms and relations from all the infinite others that compose the complete substances. In Hume, there is a de facto impossibility of stepping out of the regularity of the extrinsic causal relations,

1 PUC-Rio. Artigo recebido em setembro e aprovado em outubro.

KRITERION, Belo Horizonte, $n^{\circ}$ 108, Dez/2003, p.209-223 
which, by means of the application of general rules, ends up encompassing the whole of experience, albeit without any rational guarantee. In consequence, he confines indifference to a quasi ficticious native state of the mind, which precedes experience, or else to the limited sphere of a few situations that make this native state reappear within experience itself.

Talvez os dois filósofos mais diametralmente opostos na história da filosofia (com a nobre exceção de Heráclito e Parmênides) tenham sido Leibniz e Hume. O primeiro foi o filósofo das relações intrínsecas e onipresentes, o segundo, o filósofo das diferenças e das relações extrínsecas; o primeiro buscou estabelecer o império da razão através do princípio da razão suficiente, o segundo, os limites da razão e a contingência irredutível no fundo da experiência. Entretanto, talvez tão desconcertante quanto o fato de um período de tempo relativamente curto ter produzido pensamentos tão distintos (Hume nasceu na época da maturidade filosófica de Leibniz) sejam os pontos em seus respectivos pensamentos que conjugam essa larga distância com uma inesperada proximidade.

Um exemplo disso são suas posições simétricas em relação à noção de liberdade da vontade. Conhecemos o quanto Leibniz defende e o quanto Hume ataca essa noção. Ora, a crítica de Hume provoca, no leitor iniciante, que acabou de aprender sobre sua reformulação da teoria da relação causal, uma estranheza muito parecida (por oposição) à estranheza do leitor que vê Leibniz anunciar o vínculo indissolúvel entre a liberdade e a determinação completa das substâncias. Afinal, o princípio de razão suficiente parece à primeira vista proibir tão radicalmente a contingência e a liberdade da vontade quanto o empirismo radical parece exigir essa mesma contingência e liberdade. Entretanto, há um ponto em comum entre as duas teorias, além do espanto inverso provocado em seus leitores. Esse ponto é a crítica à idéia de uma liberdade de indiferença.

Meu objetivo aqui é fazer uma breve comparação de algumas das razões diversas subjacentes a essa crítica nos dois filósofos.

\section{Leibniz}

Nos Ensaios de Teodicéia e em diversos outros textos, Leibniz procura refutar a possibilidade da chamada "liberdade de indiferença" para assim fundamentar seu próprio conceito de liberdade. ${ }^{2}$ Essa refutação é feita, em pri-

2 Para uma abordagem mais completa de toda essa questão, ver Danowski, 2001\ 
meiro lugar, pela afirmação de que nenhuma ação poderia se dar na total ausência de razões determinantes. Sempre que há uma escolha, encontraremos um motivo que levou a ela, ainda que aparentemente a situação em que está o sujeito (seja ele um homem ou um animal irracional) se apresente como perfeitamente equilibrada. A explicação disso está, antes de mais nada, no princípio de razão suficiente, que determina que nada se faz sem uma causa ou razão. A própria vontade é constituída internamente por motivos, de modo que a concepção de que haveria na alma uma espécie de faculdade pura, capaz de se sobrepor à ausência de motivos e assim superar a indiferença por uma autodeterminação, é inconsistente e contraditória com a definição mesma de vontade. E a garantia de que o princípio de razão prevalece mesmo naquelas situações em que parecemos agir sem ter tido nenhum motivo para isso é dada pela hipótese da existência de uma infinidade de pequenas percepções que permanentemente influenciam nossa vontade ainda que não nos apercebamos delas.

Mas isso ainda não é o bastante, pois esses argumentos por si sós não afastam o risco daquilo que Pierre Bayle chamara de "armadilha do equilíbrio paralisante" , em que, justamente em virtude do princípio que impede a ação na ausência de razões, ver-nos-íamos condenados à inação nas situações em que de fato houvesse um perfeito equilíbrio e simetria. A crítica à idéia de uma liberdade de indiferença, portanto, precisa ser complementada pela recusa da própria indiferença, o que Leibniz faz demonstrando a impossibilidade da existência de uma simetria perfeita no universo como um todo e em qualquer uma de suas partes.

Essa demonstração se baseia, em primeiro lugar, no princípio leibniziano da identidade dos indiscerníveis. De acordo com esse princípio, duas substâncias nunca poderiam diferir apenas numericamente. Ao contrário, sua diferença numérica - expressa, por exemplo, em relações espacio-temporais próprias - é sempre derivada de diferenças qualitativas, determinadas pelas propriedades internas (relacionais ou não) dessas substâncias.

É preciso ... que cada mônada seja diferente de todas as outras. Pois não há jamais na natureza dois seres que sejam perfeitamente um como o outro, e em que não seja possível encontrar uma diferença interna, ou fundada em uma denominação intrínseca. (Monadologie, 9)

Sendo assim, não podemos conceber uma situação em que estivéssemos paralisados frente a duas opções absolutamente indiscerníveis: coisas rigoro- 
samente indiscerníveis seriam na verdade numericamente idênticas, ou seja, seriam uma só coisa.

Em segundo lugar, a simetria perfeita é impossível porque, no universo leibniziano, tudo está ligado a tudo. Na verdade, se não há denominações puramente extrínsecas, se toda diferença está fundada em uma denominação intrínseca, isso se deve à "conexão real de todas as coisas" (Nouveaux Essais sur l'Entendement Humain, II.XXVI.5). Como toda substância exprime em sua natureza todas as outras que formam com ela o mundo realmente existente, nenhum objeto pode ser isolado dos outros. Uma simetria restrita e localizada, se fosse possível, responderia a uma simetria generalizada de todo o universo. Assim, embora pudéssemos imaginar que os dois objetos ou fatos que se apresentam como opções ao sujeito que exercerá sua vontade, ainda que distintos um do outro, teriam, caso fossem escolhidos, o mesmo valor (em termos, por exemplo, das necessidades presentes desse sujeito, ou daquilo que ele considera o melhor), isso só poderia de fato ser o caso se esse valor se aplicasse também à totalidade das séries distintas implicadas por cada uma dessas opções, ou seja, à totalidade dos dois mundos possíveis que se tornariam reais caso o sujeito escolhesse um ou outro lado da alternativa. Mas, se fosse assim, Deus não teria tido uma razão suficiente para escolher criar apenas um desses mundos, ou seja, para criar aquele único mundo que é o melhor de todos os possíveis.

A simetria absoluta e o equilíbrio perfeito, portanto, só podem existir, para Leibniz, ali onde é possível isolar coisas de outras coisas, considerar separadamente apenas um número finito e restrito das relações que constituem um indivíduo. Em uma palavra, simetria e equilíbrio só existem no espaço geométrico, e só podem caracterizar entes de razão, ou seja, noções e conceitos incompletos. Para as substâncias completas, existentes no espaço e no tempo reais e concretos, não há indiferença, e não há, portanto, liberdade de indiferença.

\section{Hume}

Ao contrário do que se passa com Leibniz, a crítica de Hume à noção de uma indiferença da vontade vem justificar uma recusa da noção de livre arbítrio. Em sua análise do entendimento humano, Hume se ocupara em grande parte em esclarecer aquilo que podia significar a conexão necessária que acreditamos encontrar entre os objetos ou acontecimentos do mundo físico: ela não está em nenhum poder ou eficácia das próprias coisas, acessível seja à nossa razão seja aos nossos sentidos, reduzindo-se antes a um sentimento interno de determinação, provocado pelo hábito, e que leva a mente a passar de 
uma impressão presente à idéia daquele fato ou objeto que a acompanhou repetida e regularmente no passado. Nisso consiste toda a necessidade que é unanimemente atribuída aos corpos, ou às "ações da matéria" (Tratado da Natureza Humana, II.III.I.3; Investigação sobre o Entendimento Humano, VIII.I.64) ${ }^{4}$. Ora, se considerarmos as ações da mente, diz Hume, encontraremos entre elas e seus motivos a mesma conjunção constante; e embora tampouco possamos descobrir aqui um poder causativo ou necessidade essencial, não existe razão que justifique nossa afirmação da existência, neste domínio, da liberdade ou contingência que negamos ao outro.

Se se aceita a reformulação humeana da relação causal, a única forma coerente de manter a noção de livre arbítrio seria alegar que não existe entre os motivos e as ações a mesma união constante e regular que há entre os corpos. Contra isso Hume dirá que, levando-se em conta as diferenças físicas, psicológicas, sociais e culturais entre os homens, "motivos semelhantes sempre produzem ações semelhantes", exatamente como na natureza (IEH, VIII.I.65; TNH., II.III.I.5). Apenas, como nos raciocínios sobre os objetos externos, há aqui toda uma série de graus de evidência e probabilidade inferiores à prova. A contrariedade da experiência passada não revela uma contingência nas causas (fundamental, pensa Hume, para a doutrina da liberdade), mas somente diminui a probabilidade daquilo que é mais constante. E se somos incapazes em alguns casos de prever o acontecimento futuro, isso se deve a nosso desconhecimento da totalidade dos fatores (neste caso, motivos) envolvidos.

Não há nada, portanto, que aponte para a separação da evidência natural e da evidência moral como se fossem de naturezas distintas. Elas derivam dos mesmos princípios, e formam uma só cadeia, percorrida com a mesma facilidade pela imaginação. Na prática, aliás, todos - mesmo os partidários da doutrina do livre arbítrio - aceitamos esse princípio, passando de um domínio ao outro exatamente como faz o prisioneiro cuja conclusão de que sua fuga é impossível deriva igualmente da visão dos muros e barras que o cercam e de sua certeza sobre o comportamento implacável dos guardas da prisão (cf. TNH, II.III.I.17; IEH, VIII.I.70).

Mas, embora seja recusada na prática, a doutrina do livre-arbítrio é firmemente mantida na teoria, o que se explica, segundo Hume, por pelo menos três razões principais. ${ }^{5}$

Em primeiro lugar, para muitos, negar ao espírito o livre-arbítrio significava em última análise admitir a possibilidade de sua origem na própria maté-

4 Daqui em diante, respectivamente, $T N H$ e IEH.

5 Há alguma diferença entre os argumentos do Tratado e da Investigação sobre o Entendimento acerca dessas razões; mas não penso que haja incompatibilidade, e por isso os apresento aqui sem distingui-los. 
ria $^{6}$ e também, portanto, negar a imortalidade da alma, o que aparentemente minaria a base da moral cristã, fundamentada na idéia de recompensas e punições num estado futuro. Para Hume, entretanto, esse temor não se justifica: longe de representar um perigo, a necessidade, tal como ele a define, é essencial à religião e à moral. Por um lado, o mérito e o demérito atribuídos às ações supõem que os motivos de fato as influenciem, tornando a pessoa responsável por seus atos; e, por outro lado, recompensas e punições só são tidas como eficientes porque se acredita serem motivos que produzirão boas ações e desencorajarão as más. É inteiramente inconsistente, portanto, a afirmação de que a necessidade destruiria esse sistema moral.

A segunda razão é uma confusão entre os conceitos de liberdade de espontaneidade e liberdade de indiferença. Embora, ao realizar uma ação, nós reconheçamos que agimos levados por motivos, não queremos admitir que esses motivos nos determinaram de forma necessária, e que teria sido impossível agir de outra maneira. Supomos que a necessidade que atribuímos aos corpos externos resulta de um poder ou eficácia realmente presente nesses corpos; mas quando nos voltamos para nossas próprias mentes, não sentimos nada semelhante a esse poder, concluindo, aliviados, que ele simplesmente não existe, e que, portanto (uma vez que identificamos liberdade e ausência de necessidade), nossa ação foi absolutamente livre. Entretanto, diz Hume, a liberdade que nos importa preservar não é, como se pensa, a de indiferença, e sim, a de espontaneidade, que não é, como a primeira, incompatível com a necessidade. A liberdade de espontaneidade se opõe à força e à violência externa, ao constrangimento de nossa vontade por alguma coisa, algum motivo que nos impede de agir de uma certa maneira, mesmo que assim o queiramos. O que ocorre é que, como a ausência desse tipo de liberdade significa a existência desses motivos ou forças (ainda que exteriores), impedindo-nos de agir de acordo com nossa vontade, e como essa é uma preocupação legítima com que muito frequentemente temos que lidar, nós acabamos identificando liberdade em geral com total ausência de qualquer tipo de motivo, isto é com indiferença ${ }^{7}$. A verdade, no entanto, é que o fato de gozarmos da liberdade de espontaneidade não significa que não tenhamos sido determinados por motivos, não externos, mas internos à nossa própria pessoa. ${ }^{8}$

6 J. Yolton, em Thinking Matter, pp.4-ss e 14-ss, expõe o debate que teve início com Cudworth, mas que foi formulado por Locke em sua afirmação de que não haveria contradição na hipótese de Deus ter adicionado pensamento à matéria.

7 A definição de Hume para liberdade de espontaneidade, e sua afirmação de que, embora muitas de nossas ações dependam da vontade, esta última é ela mesma dependente de causas necessárias, segue de perto a teoria de Hobbes (cf. Leviathan, III-XXI).

8 Embora fale em força, constrangimento, e motivos externos e internos, Hume é pouco preciso sobre em 
Finalmente, existe "uma falsa sensação ou experiência" da liberdade de indiferença (TNH, p.II, III, II, 2; IEH, VIII.I.72 nota). Ao observarmos o comportamento e as ações alheias, quase sempre encontramos uma regularidade que nos leva a reconhecer sua determinação. Mas, no caso de nossas próprias ações, sentimos algo que parece ser uma certa indefinição [looseness] ou indiferença. A vontade "se move facilmente em todas as direções", produzindo imagens de si mesma, segundo as diversas ações representadas. E, embora apenas uma dessas imagens ou "movimentos fracos" possíveis vá se completar na própria ação, a simples existência dessas outras imagens nos faz pensar que poderíamos ter escolhido qualquer das outras opções, indiferentemente. Assim é que, por exemplo, se queremos provar nossa liberdade, bastaria "completar" uma dessas imagens, ou seja, bastaria realizar uma ação diferente da que de fato realizamos ou iríamos realizar, o que parece confirmar que a vontade não está sujeita a motivos. "Sentimos que nossas ações, na maioria das vezes, estão submetidas à nossa vontade; e imaginamos sentir que a vontade ela mesma não está submetida a nada" (TNH, ibid.). Essa "sensação" é imaginária ou falsa, pois não percebemos que, ao agir dessa maneira, isto é, ao realizar uma ação "qualquer", a nosso "bel-prazer", na verdade estamos nos submetendo a um novo motivo, tal como, neste caso, o desejo de provar nosso livre-arbítrio ${ }^{9}$. É impossível escaparmos da necessidade e da determinação. A "indefinição" ou indiferença — índices de liberdade - que acreditamos sentir dentro de nós mesmos não passam de ilusão.

Com essa recusa da idéia de liberdade de indiferença, Hume estende ao domínio da mente sua crítica à noção de acaso. Aquilo que o homem comum chama de acaso ou mesmo de contingência das causas deve ser considerado pelo filósofo - que corrige a irregularidade da experiência por meio de regras gerais extraídas dessa mesma experiência - como uma maneira imprecisa de nos referirmos à presença de causas desconhecidas. É verdade que o efeito dessas causas desconhecidas é diminuir, em graus diversos, a uniformidade da experiência passada; mas a irregularidade assim resultante poderá ser avaliada e até certo ponto reabsorvida pela regularidade, através dos raciocínios por probabilidade. Assim como não há acaso entendido como um efeito resultante da ausência de causas (o que seria pura contradição em termos), tampouco há liberdade entendida como resultado de uma indiferença da mente.

relação a que podemos falar em exterioridade e interioridade: a vontade, a mente, o corpo, a pessoa? 9 Novamente, cp. Hobbes, op.cit., I-VI. 
De acordo com minhas definições, a necessidade é parte essencial da causação; consequentemente, a liberdade, ao suprimir a necessidade, suprime também as causas, e é o mesmo que o acaso. Como normalmente se pensa que o acaso implica uma contradição, ou ao menos que é diretamente contrário à experiência, os mesmos argumentos podem sempre ser utilizados contra a liberdade ou livre-arbítrio (THN, II.III.I.18).

Em suma, não há liberdade de indiferença, porque a vontade é sempre determinada por motivos. Entretanto, isso por si só não impediria que existisse indiferença, como resultado se não da ausência de motivos, ao menos de um equilíbrio da vontade entre motivos ou causas iguais. E de fato, há ao menos três momentos de sua obra em que Hume se refere, direta ou indiretamente, à indiferença da mente ou imaginação. A consideração conjunta desses três momentos, entretanto, deixará claro que essa indiferença só é admitida por Hume em situações que de alguma forma excluem a experiência.

Hume menciona pela primeira vez o problema da indiferença para introduzir sua análise da assim chamada "probabilidade de chances", no Tratado da Natureza Humana (I.III.XI.4). Sabemos que a idéia de causa e efeito não é senão uma maior facilidade da imaginação em passar de uma impressão presente à idéia daquele objeto ou acontecimento que o hábito de uma conjunção constante na experiência passada nos faz esperar também no futuro. ${ }^{10}$ Essa facilidade da imaginação corresponde a uma dificuldade de se percorrer um caminho diferente, isto é, de se associarem as idéias de outra maneira e, mais ainda, de se crer em outras idéias. Por outro lado, a ausência de uma relação de causação constitui o que Hume, neste ponto do Tratado, chama de acaso. O acaso não é nele mesmo uma coisa real, mas apenas a negação de uma causa. Ou seja, ele desfaz o que havia sido feito pela causa, ou melhor, pelo hábito e pela conjunção constante, deixando a imaginação

inteiramente indiferente para considerar a existência ou a inexistência daquele objeto que é visto como contingente. Uma causa traça o caminho para nosso pensamento e, de certo modo, nos força a considerar objetos determinados em relações determinadas. Tudo que o acaso pode fazer é destruir tal determinação do pensamento, deixando a mente em seu estado original de indiferença, a que, na ausência de uma causa, ele retorna instantaneamente (ibid).

Mas não dissemos que Hume baseará sua crítica à doutrina do livre arbítrio na recusa do acaso, que, segundo ele, deve ser interpretado como um mero nome dado à ação de causas secretas e desconhecidas de nós? Certamente; porém a questão da liberdade só tem sentido no domínio das ações, que é ao

10 Para a versão original desse argumento, ver Danowski, 1998, pp. 194-ss. 
mesmo tempo o domínio da experiência constituída e de uma natureza humana regular e regularizada por princípios como o hábito e a associação de idéias. A situação que Hume tem em mente aqui, ao contrário, é bastante peculiar. Em primeiro lugar, a indiferença a que retornamos quando nos deparamos com o que ele chama de "ausência de causas" é, digamos assim, a situação não-marcada da mente, seu estado original (real ou lógico ${ }^{11}$ ), onde "ainda" não se estabeleceram relações de causação. Na ausência de experiência (entendida no sentido de uma conjunção constante no passado de objetos ou ações semelhantes e contíguos), a impressão presente não transmite sua força a idéias relacionadas, pois não há hábito, e não se forma uma relação natural. Não são criadas facilitações, de modo que a força e a vivacidade da impressão pode passar a qualquer idéia da imaginação. Por isso, a imaginação fica indiferente - literalmente, sem diferenças, isto é, sem facilitações nem tendências para considerar esta ou aquela idéia, e para crer nela.

Em segundo lugar, justamente por caracterizar um estado inicial que, apesar de agora inacessível, é o único em que o acaso (neste sentido negativo) pode ser considerado como regra, a indiferença só reaparece dentro da experiência como consequência de um tipo de fenômeno muito bem delimitado, e definido em grande parte a priori. O exemplo de Hume é o de um lance de dados, cujo resultado nos aparece como inteiramente indeterminado e aleatório. Em um dado perfeitamente equilibrado, diz ele, todas as seis faces têm a mesma chance de sair; sendo portanto equivalentes. A razão disso é que as "chances" em cada face são uma espécie de figura do acaso, que, sendo definido como a pura ausência de causas, não admite diferenças, de graus ou outra. Entre as diversas chances, portanto, a imaginação permanece indiferente. Ao ver um dado sendo lançado, a mente não pode se impedir de formar a imagem deste mesmo dado, com a mesma forma e características, apresentando uma e apenas uma de suas faces voltada para cima ao cair. Mas, visto que as chances nas seis faces são iguais, o pensamento considera cada uma delas, "uma após a outra, como igualmente provável e possível" (idem, I.III.XI.12); e, sendo incapaz de se fixar em apenas uma das faces, divide o impulso e a vivacidade originais das causas pelas seis partes iguais de chances ou acasos misturados a estas causas. $^{12}$

11 "Native situation". O certo é que Hume não se interessa muito por problemas de gênese. Sobre isso, ver Danowski. 1991, pp. 156-ss.

12 Note-se que aqui o acaso está misturado a uma série de causas, como por exemplo a lei de gravidade, que nos assegura que, ao soltarmos o dado, ele cairá; sua solidez, e a certeza de que ele preservará sua forma cúbica ao cair, etc. Se as causas não limitassem o acaso, nós sequer pensaríamos na possibilidade igual das seis faces saírem - pois não haveria uma relação privilegiada entre a impressão presente do lançamento do dado e as idéias dessas faces. As causas são indispensáveis para que haja algo como um 
Aquilo que gera a indiferença nesses dois casos (e apenas neles) é, portanto, a impossibilidade em que se encontra a imaginação de reunir e fundir as idéias que representam as diferentes chances ou alternativas. Isso explica por que a noção de indiferença não reaparece no restante da análise humeana da probabilidade. De fato, em uma segunda formulação do exemplo do lance de dados, um mesmo número está inscrito em duas faces e um número distinto nas outras quatro, o que permite que a imaginação junte as imagens semelhantes em uma imagem mais forte, construindo assim um raciocínio por probabilidade de chances, e escapando da indiferença. E, na "probabilidade de causas", a incerteza decorre da irregularidade da experiência passada, de tal modo que, mesmo nos casos em que os acontecimentos contrários ocorreram o mesmo número de vezes (e em que a chance dos dois eventos é portanto de $1 / 2$ ), a imaginação funde as imagens dos casos semelhantes, construindo, novamente, um raciocínio por probabilidade. ${ }^{13}$

Quando a contrariedade ou irregularidade constitui um problema, não apenas especulativo, mas também passional, temos uma situação um pouco diferente, mas que no fundo confirma o que acabamos de dizer. Se o objeto de cuja realidade temos dúvidas provoca nosso desejo ou aversão, a mente deverá sentir uma impressão momentânea de alegria ou tristeza, conforme se volte para o lado de sua existência ou para o de sua inexistência. Mas, enquanto a imaginação é extremamente ágil e capaz de alternar suas visões com rapidez, as paixões são lentas e recalcitrantes; de modo que, quando um objeto provoca alternadamente uma variedade de emoções, as paixões não se mantêm distintas. Neste caso, as visões contrárias da imaginação produzem uma mistura de alegria e de tristeza, com o predomínio de uma ou outra conforme a probabilidade, isto é, o número superior de chances ou visões se incline para o bem ou

\footnotetext{
fenômeno aleatório. Ou melhor: se não houvesse nenhuma causa, evidentemente só haveria acaso e indiferença, mas estes estariam espalhados indistintamente por toda a experiência (que sequer, aliás, poderia ser dita experiência em sentido forte). Ao vermos um dado, poderíamos, por exemplo, formar a idéia de seu estilhaçamento, ou uma outra idéia completamente distinta. A força e a vivacidade da impressão presente se dividiriam, não em seis, mas em infinitas partes iguais, ou então sequer se dividiriam. É isto que caracteriza o estado original de indiferença da mente: "Ali onde nada limita as chances, todas as noções que a fantasia mais extravagante é capaz de formar estão em pé de igualdade..." (TNH, I.III.XI.6).

13 Há um trecho na seção do Tratado sobre a liberdade da vontade que parece contradizer minha afirmação de que a indiferença só tem lugar na experiência em um domínio muito restrito. De fato, embora fale aqui em "acaso ou indiferença", a situação a que Hume se refere corresponde, não ao primeiro tipo de probailidade de chances, mas à probabilidade de causas: "Mesmo quando essas experiências contrárias são exatamente equivalentes, não suprimimos a noção de causas e necessidade; supomos que a contrariedade usual decorre da operação secreta de causas contrárias, e concluímos que o acaso ou indiferença se deve a nosso conhecimento imperfeito e está apenas em nosso julgamento, não nas próprias coisas, as quais são igualmente necessárias em todos os casos, ainda que não apareçam de maneira igualmente constante ou certa" (ibid., II.III.I.12). Entretanto, o termo "indiferença" aqui utilizado tem estritamente a função de associar o acaso à liberdade da vontade, introduzindo assim a questão da chamada "liberdade de indiferença".
} 
para o mal. Esperança e medo são produtos dessa mistura de alegria e tristeza, correspondendo à maior ou menor probabilidade de existência ou inexistência do objeto do desejo ou aversão.

Mas nem sempre a existência simultânea de alegria e tristeza produz esse tipo de mistura. Quando derivam de objetos inteiramente diferentes, as paixões contrárias sucedem-se alternadamente. A ausência de relação de idéias separa as impressões e impede sua oposição ou influência mútua. Um homem que esteja ao mesmo tempo aflito pela perda de uma causa e feliz com o nascimento de um filho dificilmente poderá temperar um afeto com o outro. Mesmo a mente passando rapidamente do objeto agradável ao desagradável, elas permanecem distintas "como dois licores opostos mantidos em garrafas diferentes" (TNH, II.III.IX.17). Quando as paixões procedem de partes diferentes do mesmo objeto (isto é, quando ele contém algo adverso e algo favorável), elas se misturam devido à relação existente entre suas causas respectivas; porém, ao se misturarem, tornam-se mutuamente destrutivas ("como um álcali e um ácido"), deixando a mente em perfeita "tranquilidade" ou "indiferença" (ibid., II.III.IX.14 e 15).

Notemos, antes de mais nada, que a indiferença a que Hume se refere aqui não é a mesma que caracterizava o estado original da imaginação, e que decorria da total incerteza acerca da existência ou inexistência futura de um determinado objeto ou evento. Em nenhum dos dois casos que acabamos que descrever há incerteza sobre a existência do objeto. Por isso o sentido aqui da palavra "indiferença" é, antes, justamente, o de tranquilidade. Mas tampouco há indiferença (no sentido próprio) no caso em que o objeto é considerado provável ou improvável em um certo grau. Pois, nesse caso, as paixões contrárias estarão presentes ao mesmo tempo na mente e, ao invés de temperar, equilibrar ou destruir uma a outra, subsistirão juntas, produzindo um terceiro afeto por sua união: a esperança ou o medo. E quando as chances são iguais dos dois lados, e a incerteza a maior possível, é então que as paixões de medo e esperança surgem com sua força máxima, uma vez que a mente, sem ter um fundamento em que se fixar, é jogada de um lado para o outro com a maior incerteza. Por exemplo, temos medo de que o acontecimento venha a existir, e esperança de que não venha a existir. Qualquer diferença no grau de probabilidade entre os lados desequilibra também essa distribuição das paixões, aumentando e diminuindo respectivamente os graus da esperança e do medo ou vice-versa.

Mas como conciliar a indiferença com que Hume caracterizava o primeiro tipo de probabilidade de chances, em que havia também uma total incompatibilidade entre os diferentes lados, com nossa afirmação de que não há uma indiferença nas paixões? No caso específico da probabilidade, as chances se 
referiam a eventos ou objetos distintos (no lance de dados, às diferentes faces ou números), e embora fossem iguais enquanto chances, também eram incompatíveis ${ }^{14}$. Mas consideremos um lance de dados do ponto de vista das paixões. Suponhamos que eu aposte uma boa quantia no número quatro. Eu sei que as chances são iguais nos seis lados, e que a probabilidade de ganhar será de 1/6. Ao considerar o possível resultado desejado, portanto, tenho alguma esperança e muito mais medo. Mas note-se que a questão no livro I do Tratado não era qual a chance de tal ou tal número sair, e sim que número iria sair. Neste caso, a incerteza pura e simples da imaginação predominará, e nem a esperança nem o medo terão lugar. Trata-se de uma situação anterior à aposta, e, por isso, meu único interesse parece ser especulativo - um interesse que diria respeito a minhas paixões calmas, talvez à de curiosidade.

Suponhamos agora que eu aposte em três números ao mesmo tempo. Teremos então três chances contra três, e o resultado para a imaginação será novamente a indiferença. Qual o efeito disso para as paixões ? Ao ver o dado sendo lançado, e ao percorrer em minha mente as imagens dos seis lados, três das quais me dão prazer e três desprazer, as paixões respectivas de alegria e tristeza se transformarão em iguais graus de esperança e medo, os quais, entretanto, segundo Hume, não se anularão, mas existirão simultaneamente. $\mathrm{Ou}$ seja, a incerteza produzida pela contrariedade tem efeitos diferentes sobre a imaginação e sobre as paixões: nestas últimas não há lugar para a indiferença, já que há esperança e medo.

Ao descrever pela primeira vez o mecanismo das probabilidades, Hume não estava levando em conta o problema das paixões. O lance de dados e seus resultados não implicavam qualquer prazer ou desprazer; os barcos voltando ou deixando de voltar ao cais (exemplo da probabilidade de causas) não eram fonte de contentamento ou amargura. Tratava-se simplesmente de uma questão especulativa, um problema de crença. Indiferença significava então ausência de determinação e de tendência a considerar um objeto ou um lado em particular do objeto. A força da impressão, lembremos, fica dividida igualmente entre todas as chances. $\mathrm{Na}$ especulação, mesmo um resultado inteiramente aleatório e incerto não é fonte de nenhuma emoção especial; mas se estamos fazendo uma aposta, tudo muda de figura. Nenhum resultado, nenhum evento é em parte bom e em parte ruim. O que há é uma incerteza sobre se o resultado bom existirá ou não, e qualquer resultado será ou bom ou ruim. Ao lançarmos o dado, temos medo de que o número em que apostamos não saia, e esperança de que ele saia, e viceversa. Como ficar indiferente diante dessas possibilidades?

14 A não ser no segundo tipo de probabilidade de chances e na probabilidade de causas. 
As paixões, portanto, embora dêem uma nova dimensão à mente, uma dimensão que não aparece com a mera análise do entendimento, confirmam nossa hipótese: a indiferença em sentido estrito (e com ela o acaso) só pode existir no empirismo humeano enquanto caracteriza um estado da mente anterior ou exterior à experiência. Se podemos sempre ao menos supor idéias e impressões (inclusive prazer e dor) aparecendo pela primeira vez a um homem, assim como uma imaginação independente do hábito e da causação, é impossível fazer o mesmo tipo de suposição em relação às paixões. É possível, sim, haver objetos que não nos dão nem prazer nem desprazer, e que nos são indiferentes neste sentido, a saber, não interessam nem despertam nossas paixões. Mas como sentir medo de algo se não temos idéia de seus efeitos? Como desejar um objeto se não sabemos que nos proporcionará prazer? Em outras palavras, como haver paixões onde não há experiência em sentido forte, e onde não realizamos inferências de causa e efeito?

\section{Leibniz e Hume}

Para concluir, vemos que, em Leibniz como em Hume, uma vez que a vontade não tem o poder de se auto determinar, a possibilidade ou impossibilidade da indiferença depende diretamente do tipo de relação que se estabelece entre os termos que formam a alternativa em questão, e, além disso, no caso de Hume, da possibilidade ou impossibilidade de se estabelecerem essas relações. Em Leibniz, a indiferença real é uma situação "quimérica", porque dependeria da existência de uma simetria perfeita, possível exclusivamente no domínio restrito das noções de razão, mas impossível (e aliás indesejável) nas substâncias completas. A razão disso, como vimos, é que, como todas as relações ou são intrínsecas ou se exprimem em relações intrínsecas, e como tudo está ligado a tudo, não podemos isolar um termo de todas as suas infinitas relações com o conjunto de substâncias que compõem o mundo real em que esse termo está inserido.

Em Hume, embora as relações causais (que são as que importam para a formação da crença e, portanto, também para a indiferença) sejam todas extrínsecas aos termos relacionados, uma vez que estejamos inseridos dentro da experiência tampouco podemos isolar completamente um fato ou acontecimento de outros. Há apenas três tipos de situação que parecem indicar esse isolamento dentro da experiência ${ }^{15}$. O primeiro são acontecimentos casuais.

15 É bem verdade que Hume tem um certo fascínio por situações que parecem representar um suposto ponto zero da experiência, em que os objetos e o mundo apareceriam pela primeira vez a um observador. Assim, 
Mas o acaso, como vimos, pode e deve ser tratado pela filosofia como uma irregularidade decorrente da ação de causas que desconhecemos; o acontecimento aparentemente isolado na verdade está inserido em uma rede de relações do mesmo tipo que os acontecimentos mais regulares. O segundo tipo são os milagres, que reivindicam o direito ao isolamento ao se situarem sobre a natureza; Hume, entretanto, argumenta que, exatamente por essa recusa em se inserir no domínio da natureza, os supostos acontecimentos milagrosos não fazem jus à sua pretensão de se constituirem em objetos de crença, a qual seguirá sempre, de preferência, a regularidade daquela. ${ }^{16}$ Finalmente, há essas situações muito bem delimitadas, como a do lance de dados, que fazem a mente recair momentaneamente em seu estado original. Mas então, justamente, não estamos falando de experiência em sentido próprio.

No estado original da mente, como todas as coisas são ainda desconexas e soltas, e sobretudo como ainda não há repetições, não há relações privilegiadas, de modo que a imaginação não tem nada que a incline mais a um lado que a outro, ou seja, que a incline a crer que um lado tem uma probabilidade maior de ocorrer que o outro. A indiferença decorre dessa ausência de relações causais. No lance de dados, a indiferença reaparece como uma espécie de perplexidade, em que a mente se vê diante de termos que, sendo perfeitamente iguais uns aos outros (in-diferentes), permanecem irrelacionáveis, uma vez que têm todos a mesma chance ou possibilidade de "sair", ou seja, de existir, ao passo que a realidade só permite que um deles exista. Para usarmos a linguagem leibniziana, é como se todas as faces do dado tivessem exatamente a mesma pretensão à existência (para a mente), sendo entretanto incompossíveis (lógica e realmente). O resultado é a indiferença da mente. Mas essa indiferença é uma situação excepcional, limitando-se a um domínio restrito e bem definido, uma espécie de enclave a priori ou atemporal no interior da experiência. Não é por acaso que essa forma do lance de dados é o único momento, em toda a sua análise do mecanismo das probabilidades, em que Hume não se refere às chances como representativas de fatos passados. Quando representam fatos, as chances se comportam como qualquer objeto no sistema humeano: acumu-

\footnotetext{
por exemplo: "se uma pessoa adulta e de natureza igual à nossa fosse subitamente transportada para nosso mundo..." (THN II.I.VI.9); "Se um homem como Adão fosse criado com todo o vigor de seu entendimento, mas sem experiência..." (Sinopse, 11); "Se alguém fizesse abstração de tudo o que sabe ou viu..." (Diálogos sobre a Religião Natural, II); "Se um estranho chegasse de súbito a este mundo..." (idem, X, p.133). No entanto, ao mesmo tempo em que apontam para a total impossibilidade de obtermos qualquer tipo de garantia acerca da regularidade da experiência, o caráter abertamente ficcional dessas cenas deixa claro que nós, ao contrário desses personagens, estamos de fato sempre já inseridos na experiência (tomada em um sentido geral), bem como dos hábitos e crenças por ela gerados. Ver Danowski, 1991, cap. 5.

16 Para uma abordagem mais completa desse problema, ver meu artigo "David Hume e a questão dos milagres." (Danowski 1995)
} 
lam-se, ou antes se fundem, isto é, são unidas pela imaginação, gerando assim um hábito e, finalmente, a crença.

De um lado, portanto, a ligação harmônica entre todas as substâncias individuais concretas que formam o melhor dos mundos possíveis, ligação que se dá por meio de relações expressas no interior do conceito completo de cada uma dessas substâncias. De outro, a impossibilidade de fato de escaparmos da regularidade das relações extrínsecas, que, pela aplicação das regras gerais, acabam por se estender a toda a experiência, ainda que sem garantias racionais. A indiferença em Leibniz só é possível no domínio das noções de razão, ou seja, das noções incompletas, em que podemos privilegiar e isolar termos e relações uns dos outros. Em Hume, ela só é possível na situação quase fictícia de um estado anterior à experiência, onde não há repetições gerando hábitos, inclinações e crenças na imaginação - em uma palavra, gerando relações causais - ou então no afloramento desse estado no interior da experiência, no domínio restrito de situações em que, embora os termos incompatíveis sejam qualitativamente idênticos, eles não são capazes de constituir para a imaginação aquele tipo de repetição que caracteriza a experiência, ou seja, não se relacionam nem se unem na imaginação para gerar hábitos ou crenças.

\section{Bibliografia}

Bayle, P. Dictionnaire historique et critique, Paris: Desoer. 1820.

Danowski, D. Natureza Acaso: a contingência na filosofia de David Hume. Tese de doutorado, PUC-Rio de Janeiro. 1991.

_ “David Hume e a questão dos milagres.” Manuscrito, XVIII (1): 37-64. 1995.

"Deleuze avec Hume". In: E. Alliez (org.), Gilles Deleuze: une vie philosophique. Paris: Les Empêcheurs de Penser en Rond: 191-206. 1998.

"Indiferença, simetria e perfeição segundo Leibniz." Kriterion, XLII (104): 49-71. 2001.

Hobbes, T. Leviathan. Harmondsworth, Middlesex: Penguin. 1980.

Hume, D. Tratado da Natureza Humana. São Paulo: Editora UNESP, 2001.

- Sinopse... São Paulo: Editora UNESP, 2001.

An Enquiry concerning Human Understanding. Oxford: Clarendon Press. 1986. Diálogos sobre a Religião Natural. São Paulo: Martins Fontes. 1992.

Leibniz, G.W. Essais de Théodicée. Paris: Garnier-Flammarion. 1969.

—La Monadologie. Paris: Delagrave. 1998.

_ Nouveaux Essais sur l'Entendement Humain. Paris: Garnier-Flammarion. 1990.

Yolton, J., Thinking Matter: materialism in eighteenth-century Britain, Minneapolis:

University of Minnesota Press. 1983. 